\title{
The Effect of Standing and Kneeling Postures on Muscle Activity for Squat
}

\author{
Taewoong Jeong ${ }^{a}{ }^{\circledR}$, Yijung Chung ${ }^{b}$ \\ aDepartment of Physical Therapy, The Graduate School, Sahmyook University, Seoul, Republic of Korea \\ ${ }^{b}$ Department of Physical Therapy, College of Health and Welfare, Sahmyook University, Seoul, Republic of Korea
}

Objective: This study aimed to identify the effects of assuming two types of posture (standing and kneeling) during squat exercise on lower body muscle activity.

\section{Design: Cross-sectional study}

Methods: Twenty-five healthy adults (18 men and 7 women) were instructed to perform the squat exercises while assuming two types of posture (standing and kneeling). EMG (Electromyography) data (\% maximum voluntary isometric contraction) were recorded three times from the rectus femoris (RF), gluteus maximus (GMax), gluteus medius (GMed) and biceps femoris (BF) of participant's dominant side and the mean values were analyzed.

Results: During the squat exercise with all postures, there was statistically significant difference on rectus femoris, gluteus maximus, gluteus medius, and biceps femoris muscle activity $(\mathrm{p}<0.05)$. The results showed that, there was significantly greater rectus femoris, gluteus medius, and biceps femoris muscle activity in standing posture than in kneeling position ( $<<0.05$ ). However, the gluteus maximus muscle activity was significantly greater with kneeling posture compared to standing posture $(\mathrm{p}<0.05)$.

Conclusions: With standing posture, it is showed that rectus femoris, gluteus medius, and biceps femoris muscle activity was greater than kneeling position. While the gluteus maximus muscle activity with standing posture was less than with kneeling posture. Therefore, it is considered that this study can be used as a selective indicator of exercise posture for strengthening specific muscle or weakness caused by paralysis.

Key Words: Muscle Strength, Electromyography, Lower Extremity

\begin{abstract}
서론
무릎 서기, 반 무릎 서기, 무릎 서기에서 반 무릎 서기 자세로 전환, 무릎 서서 보행과 같은 무릎 훈련은 물리치 료에서 일상적으로 사용되고 있다[1]. 무릎 서기 훈련은 기능적 이동성 회복을 위한 중재의 한 방법으로 사용되고 있다. 또한 무릎 서기 훈련은 순차적인 자세 발달을 위한 중재[2], 이동을 위한 준비 활동[3], 과도기 패턴에 대한 보조 치료[4] 중 하나로 사용된다. 한 연구에서 근전도를 사용하여 건강한 피험자의 몸통 폄 운동을 하는 동안 무 릎 서기와 정상적인 서 있는 자세의 근육 활동을 비교했 을 때 동등한 몸통 근육 활동에도 불구하고 정상적인 서
\end{abstract}

기에 비해 무릎 서기 자세에서 신전 기능이 감소하는 것 으로 나타났다[7].

무릎 서기 자세에서 무릎 굽힘근과 무릎 폄근은 일반적 으로 서 있거나 앉은 자세와 비교하여 다양한 요구 사항 을 경험할 것이다[6]. 무릎 서기 자세 동안 안정성 제어에 대한 지식은 물리 치료사에게 유용하다[7]. 예를 들어, 환 자는 무릎 서기 자세를 훈련하여 일어나기 위한 적절한 시너지 효과를 확립하고 강화할 수 있다[8]. 무릎 서기 자 세에서의 물리치료는 보행 중 정면에서 자세 정렬을 안정 시키기 위한 엉덩이 근육 긴장도(예: 중간볼기근)의 촉진 에 초점을 맞출 수 있다. 또한 무릎 서기 자세에서 질량 중심이 지면에 더 가깝게 위치하여 안정화가 더 쉽기 때 
문에 무게중심의 변동성이 감소된다[7].

정상 성인이 균형을 유지하기 위한 두 가지 선택적 자세 전략으로 발목 전략(발목 관절 움직임에 의해 신체의 무 게중심 이동)과 엉덩이 전략(엉덩이 관절 움직임에 의해 무게중심 이동)이 알려져 있다[5]. 무릎 서기 자세에서는 발목 전략을 사용할 수 없으며 똑바로 세운 자세를 유지 하기 위해 엉덩이 조절에 의존해야 한다. 즉, 무릎 서기 자세는 몸통/엉덩이 제어를 사용해야 한다. 이것은 몸통 제어와 엉덩이 안정근들을 강화하기 위한 무릎 서기 훈련 의 임상적 관련성을 설명할 수 있다[1]. 무릎 서기 훈련이 자주 사용됨에도 불구하고 이러한 훈련 효과를 뒷받침하 는 임상적 증거는 많이 부족한 실정이다. 따라서 본 연구 는 건강한 성인을 대상으로 두 가지 자세에서 적용한 스 쿼트가 하지 근활성도에 미치는 영향을 알아봄으로써 향 후 운동 처방의 기초 자료를 제시하고자 한다.

\section{연구방법}

\section{연구대상}

본 연구는 건강한 성인을 대상으로 선정 기준에 부합하 는 25 명의 대상자를 선정하여 실험을 진행하였다. 대상자 모집은 순천향대학교 부천병원 게시판에 실험 참가자 모

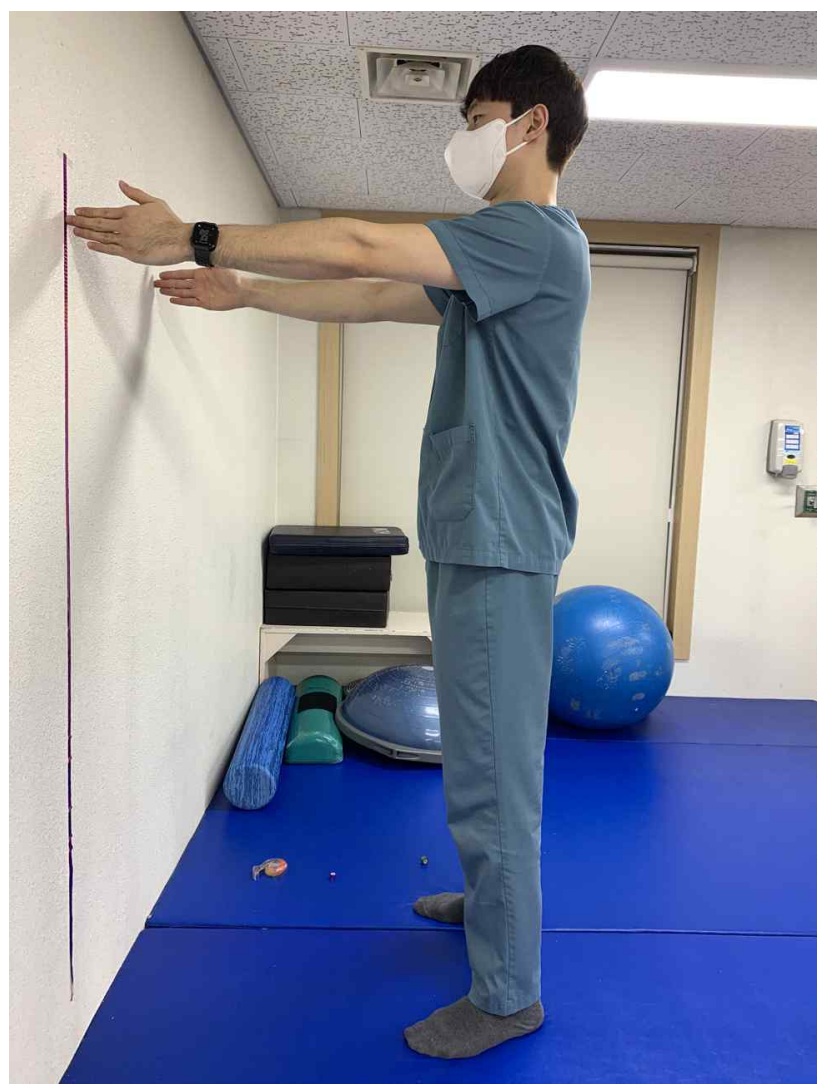

Figure 1.
집 공고문을 부착하고 자발적 지원을 받아 모집하였다. 실험 전 연구 대상자들은 실험절차와 조건에 대하여 설명 을 듣고, 연구 참여 동의서에 서명하였다.

대상자 선정 기준은 최근 6개월 이전에 무릎 통증을 경험하지 않은 사람, 신경계 질환을 경험하지 않은 사 람, 양측 하지에 정형외과적 질환이 없는 사람으로 하였 으며 대상자 제외 기준은 신경계 질환이 있는 사람, 암 이나 임신 등으로 운동 수행이 불가능한 사람으로 하였 다[6]. 본 연구는 삼육대학교 연구윤리위원회에서 승인 (2-1040781-A-N-012021061HR)을 받은 후 진행하였다.

\section{연구절차}

\section{측정방법}

바로 선 자세에서 스쿼트를 수행하는 동안 양쪽 발의 간 격은 어깨너비로 벌리고 어깨뼈봉우리돌기(acromion process) 와 가쪽 복사뼈(lateral malleolus)가 수직으로 위치하도록 하였다(Figure 1). 무릎 서기 자세에서 스쿼트를 수행하는 동안 양 무릎의 간격은 골반 너비로 벌리고 어깨뼈봉우리 돌기와 넙다리뼈가 수직선을 따르도록 무릎을 위치시키고 무릎과 발목관절이 일직선이 되도록 다리를 평행한 위치 에 놓았다(Figure 2). 두 자세 모두 시선은 정면을 응시하

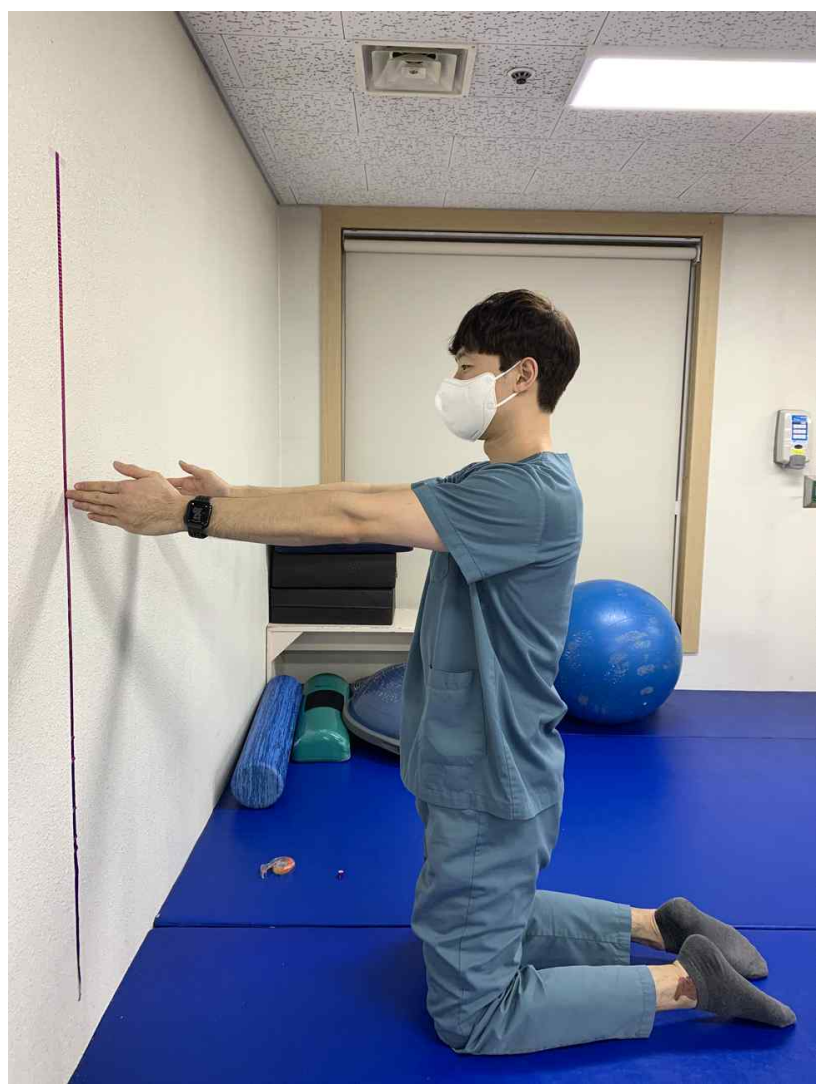

Figure 2. 
도록 하였으며 벽에 수직으로 부착된 가이드라인에 뻗은 손가락 끝이 닿도록 유지하였다. 스쿼트 동작을 수행하는 방법에 대한 설명은 다음과 같다.

바로 선 자세에서 스쿼트의 경우 무릎 굴곡 각도는 $90^{\circ}$ 로 설정하였으며 무릎 서기 자세에서 스쿼트의 경우 엉덩 이가 발뒤꿈치에 닿지 않도록 일정량의 무릎 굴곡을 설정 하였다(Figure 3). 또한 $1 \mathrm{~cm}$ 두께의 요가 매트를 사용하 여 무릎 서기 스쿼트 중 무릎 통증을 예방하였다[13]. 피 험자들은 3 초간 편심성 수축, 3 초간 등척성 수축, 3 초간 동심성 수축을 통하여 총 9초 동안 스쿼트를 진행하였다. 9 초 중 중간 7 초의 데이터만 분석에 사용하였다. 근피로 를 최소화하기 위하여 실험 사이 1 분간의 휴식을 제공하 였다. 대상자는 바로 선 자세와 무릎 서기 자세에서 각각 3 회의 스쿼트를 수행하였다. 또한 스쿼트 수행 순서의 영 향을 방지하기 위해 스쿼트를 무작위 순서로 수행하였다. 대상자는 실험 전 스쿼트에 대한 충분한 설명을 들었으며, 스퀴트 동작을 숙지할 수 있도록 사전 연습이 이루어진 후 실험을 진행하였다.

\section{측정도구}

\section{근활성도}

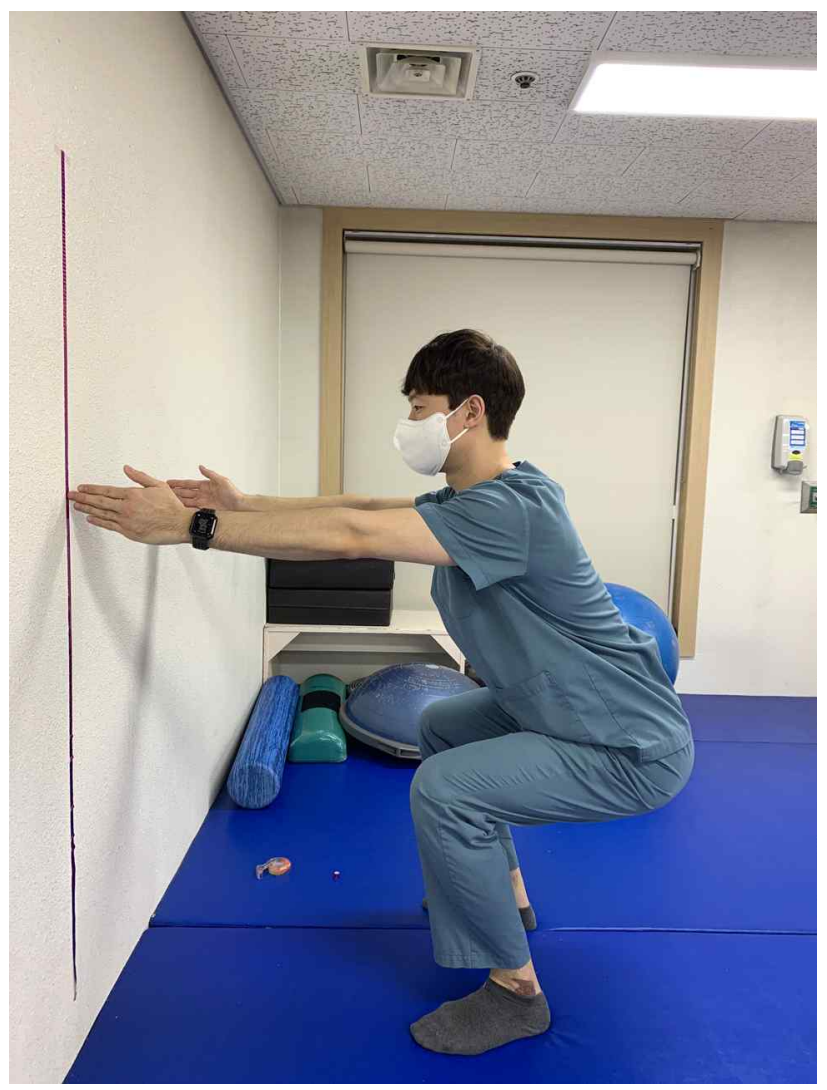

Figure 3. 넙다리곧은근(rectus femoris), 큰볼기근(gluteus maximus), 중간볼기근(gluteus medius), 넙다리두갈래근(biceps femoris)의 근활성도를 측정하기 위해 표면 근전도 (Telemyo 2400 G2, Noraxon, U.S.A)를 사용하였다. 근 전도 신호의 표본 추출률(sampling rate)은 $1500 \mathrm{~Hz}$ 로 설 정하였고, 주파수 대역폭은 20-500 Hz로 하였다. 본 연구 에서 측정한 근전도 신호는 정파 정류(full wave rectification)로 처리한 후 실효값인 RMS (root mean square) $300 \mathrm{~ms}$ 값을 취하였으며 Myoresearch XP master edition 소프트웨어(Noraxon Inc, Arizona, U.S.A)를 이용 하여 분석하였다[6].

전극의 부착 위치는 넙다리곧은근의 경우 무릎벼(patella) 의 중심과 위앞엉덩뼈가시(anterior superior iliac spine) 사이 중간에 부착하였고 큰볼기근의 경우 큰돌기(greater trochanter)와 천추(sacrum)의 중간 부위의 큰돌기 높이에 서 $3 \mathrm{~cm}$ 의 거리를 두고 근섬유와 평행하도록 비스듬하게 부착하였다. 중간볼기근의 경우 엉덩뼈능선(iliac crest)과 큰돌기 사이의 근위부 3 분의 1 지점에서 $2 \mathrm{~cm}$ 간격을 두고 근섬유에 나란히 부착하였고, 넙다리두갈래근의 경우 넙 다리 후면부에서 무릎과 볼기고랑(gluteal sulcus)의 중간 지점에 $2 \mathrm{~cm}$ 간격을 두고 근섬유와 평행하도록 부착하였 다[11].

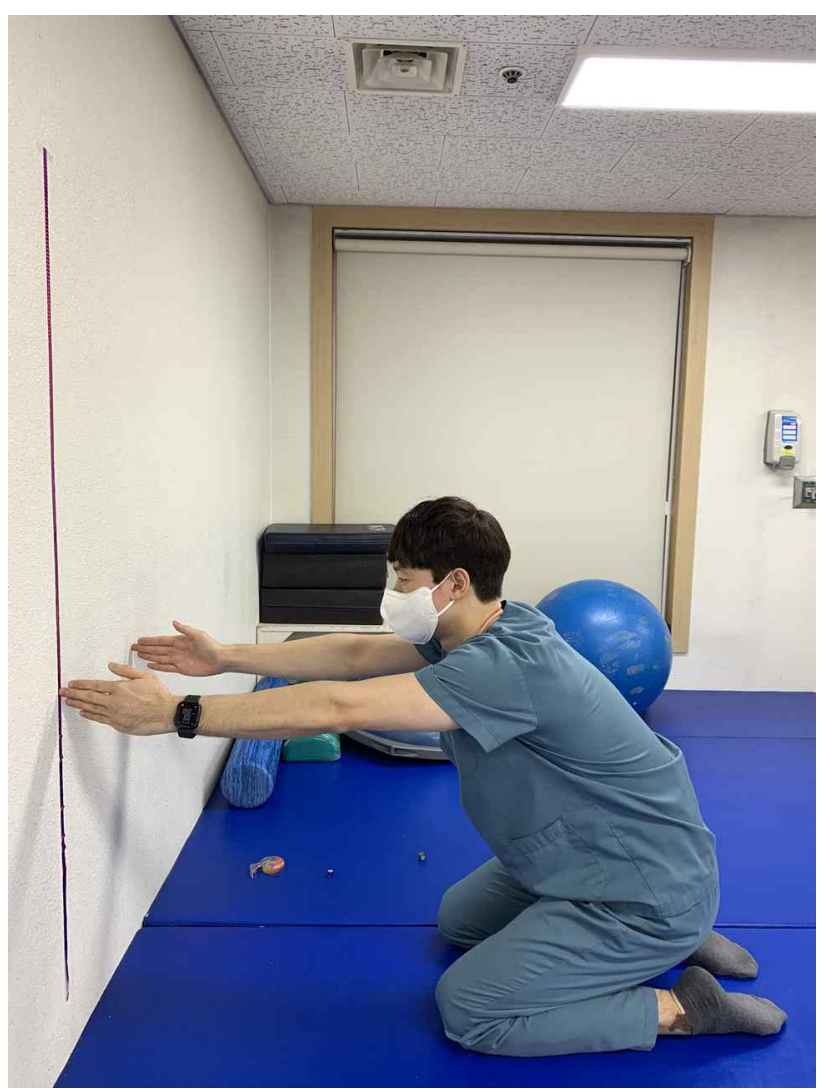

Figure 4 . 
전극 부착 전 피부 저항을 최소화하기 위하여 털을 제거 하고 알코올 솜으로 부착부위를 닦아주었다. 모든 대상자 들의 우세 측 최대 자발적 등척성 수축인 MVIC (maximum voluntary isomeric contraction)를 측정하였으며 각 근육 의 측정 자세 및 각도는 도수근력 검사(manual muscle test)를 기준으로 하였다. 넙다리곧은근은 바로 누운 자세 에서, 중간볼기근은 옆으로 누운 자세에서, 큰볼기근, 넙 다리두갈래근은 엎드려 누운 자세에서 개별적으로 측정되 었다[12]. \%MVIC 값으로 정규화 하기 위하여 9초의 운 동 중 앞, 뒤 1 초를 제외하고 가운데 7 초 구간의 근전도 신호를 사용하여 MVIC 값으로 나누었다.

\section{자료분석}

본 연구의 통계와 모든 작업은 SPSS(version 18.0, IBM Co., USA)를 이용하여 평균과 표준편차를 산출하 였다. 대상자의 일반적 특성은 기술 통계를 사용하였다. 스쿼트 중 바로 선 자세와 무릎 서기 자세가 하지 근활성 도에 미치는 영향을 비교하기 위해 대응 표본 $\mathrm{t}$ 검정 (paired t test)을 실시하였다. 모든 자료의 통계학적 유의 수준 $(\alpha)$ 은 0.05 이다.

\section{연구 결과}

대상자는 총 25 명으로 남자 18 명, 여자 7명, 평균 연령 은 35.32 세, 평균 신장은 $172.36 \mathrm{~cm}$, 체중은 $70.28 \mathrm{~kg}$ 이었 다(Table 1).

바로 선 자세에서 스쿼트와 무릎 서기 자세에서 스쿼트

Table 1. General characteristics of subjects

$(\mathrm{N}=25)$

\begin{tabular}{ll}
\hline & Subjects \\
\hline Gender (male/female) & $18 / 7$ \\
Age (years) & $35.32(7.32)$ \\
Height $(\mathrm{cm})$ & $172.36(9.15)$ \\
Weight $(\mathrm{kg})$ & $70.28(10.18)$ \\
\hline
\end{tabular}

The values are presented as mean (SD)

Table 2. Muscle activity in each position during squat

\begin{tabular}{lllll}
\multicolumn{1}{l}{ Table 2. Muscle activity in each position during squat } & & (N=25) \\
\hline & Standing (\%MVIC) & Kneeling (\%MVIC) & t & p \\
\hline Ructus femoris & $31.96(11.05)$ & $15.33(13.11)$ & 6.766 & $<0.001^{*}$ \\
Gluteus maximus & $8.62(6.31)$ & $18.03(13.9)$ & -4.707 & $<0.001^{*}$ \\
Gluteus medius & $36.17(21.89)$ & $10.27(6.12)$ & 5.747 & $<0.001^{*}$ \\
Biceps femoris & $15.47(12.5)$ & $8.75(5.29)$ & 3.025 & $0.006^{*}$ \\
\hline
\end{tabular}

The values are presented as mean (SD)

${ }^{*}$ Conditions that showed a significant difference from squat in standing posture $(p<0.05)$.
시 넙다리곧은근, 큰볼기근, 중간볼기근, 넙다리두갈래근 모두 통계적으로 유의한 차이가 나타났다 $(\mathrm{p}<0.05)$. 넙다 리곧은근, 중간볼기근, 넙다리두갈래근의 근활성도는 바로 선 자세에서 스쿼트가 무릎 서기 자세에서 스쿼트보다 유 의하게 크게 나타났으며 $(\mathrm{p}<0.05)$, 큰볼기근의 근활성도는 무릎 서기 자세에서 스쿼트가 바로 선 자세에서 스쿼트보 다 유의하게 크게 나타났다 $(\mathrm{p}<0.05)($ Table 2).

\section{고찰}

본 연구에서는 건강한 성인을 대상으로 스쿼트 시 바로 선 자세와 무릎 서기 자세가 하지 근활성도의 변화에 미 치는 영향을 비교하고자 하였다.

넙다리곧은근, 중간볼기근, 넙다리두갈래근의 근활성도는 바로 선 자세에서 수행하는 스쿼트에서 무릎 서기 자세에 서 수행하는 스쿼트보다 유의하게 크게 나타났다 $(\mathrm{p}<0.05)$. Gallagher 등[10]에 따르면 등척성 및 등속성 수축 등의 힘은 모두 바로 선 자세에 비해 무릎 서기 자세에서 크게 감소한다고 보고했다. 이는 생체 역학의 변경으로 인해 무릎 서기 자세에서 안정성이 증가한 결과로 예상할 수 있다. 예를 들어, 질량 중심이 지면에 더 가까이 위치하게 되면 생체 역학 시스템 변경으로 자세의 불안정성을 감소 시킨다[7]. 그럼에도 불구하고 몸통 근육의 근활성도는 유 사하게 측정되었다. 이 결과는 바로 선 자세와 동등한 힘 을 얻기 위해 무릎 서기 자세에서 몸통 근육이 더 강한 활성화를 생성해야 함을 시사한다[1].

큰볼기근의 근활성도는 무릎 서기 자세에서 수행하는 스쿼트가 바로 선 자세에서 수행하는 스쿼트보다 유의하 게 증가하였다 $(\mathrm{p}<0.05)$. Kurayama 등[1]은 무릎 서기 보행 중 큰볼기근 활동은 정상적인 보행보다 크게 나타났 다고 보고했다. 이 결과는 무릎 서기 자세로 인해 안정성 이 증가되어도 근위부의 근활성도는 증가됨을 나타낸다. 이는 다관절 근육이 많은 원위부에 비해 단관절 근육이 많은 근위부의 경우 움직임을 보조하는 근육의 수가 줄어 들고 바로 선 자세와 동등한 힘을 얻기 위해 몸통 근육의 안정화를 돕기 위한 것으로 생각된다[10]. 
큰볼기근과 다르게 중간볼기근의 근활성도는 바로 선 자세에서 수행하는 스쿼트가 무릎 서기 자세에서 수행하 는 스쿼트보다 유의하게 증가하였다 $(\mathrm{p}<0.05)$. 무릎 서기 자세에 비해 바로 선 자세는 무게중심이 높고 지지 기반 이 작아 자세 안정성이 떨어져 몸통의 자세 제어를 위해 중간볼기근의 힘 요구를 증가시킨 것으로 보인다. 이러한 몸통의 흔들림을 방지하고 안정성을 증가시키기 위하여 중간볼기근의 근활성도가 증가하였다고 볼 수 있다.

서로 다른 자세에 의해 제공되는 지지 기반과 무게중심 의 높이가 허벅지 근육 활동에 영향을 미친다고 볼 수 있 다. 바로 선 자세의 지지 기반은 발바닥으로만 구성되었 으며 무릎 서기 자세보다 현저히 작았다. 결과적으로 바 로 선 자세와 비교할 때 무릎 서기 자세의 안정성 증가는 엉덩이와 무릎 관절을 안정화하기 위한 허벅지 근육의 힘 요구를 감소시킨 것으로 보인다.

무릎 서기 자세에서는 발목의 움직임을 사용할 수 없 다. 즉 무릎 서기 자세에서 발바닥과 발목의 고유 수용성 감각 입력은 균형을 제어하는 데 사용할 수 없다. Mezzarane 등[7]은 무릎 서기 자세 제어가 시각 및 전정 입력 외에도 무릎 관절(예: 허벅지 근육)과 관련된 구조에 서 나오는 체성 감각 입력에 의존해야 한다고 지적했다. 이러한 장점은 바로 선 자세보다 무릎 서기 자세가 신경 계 환자들에게 적용했을 때 무릎 관절과 관련된 체성 감 각의 증진에 효과가 있을 것으로 생각된다. 또한 무릎 서 기 자세는 바로 선 자세보다 높이와 무게중심이 낮고 지 지 기반이 증가되기 때문에 넘어질 위험이 감소한다. 무 릎 서기 자세는 다른 관절에 불가피하게 영향을 미치는 발목 전략의 효과를 제거할 수 있는 장점도 존재한다. 하 지만 정적인 무릎 서기 자세를 15 분 이상 계속하면 허리 통증이 발생할 수 있다는 점은 주의해야 한다[12].

본 연구에서는 바로 선 자세와 무릎 서기 자세가 하지 근활성도의 변화에 미치는 영향을 비교하고자 하였다. 하 지만 해당 자세의 차이는 하지 뿐만 아니라 몸통 근육에 도 많은 영향을 받을 수 있기 때문에 두 자세 간의 차이 를 일반화하기에는 제한적이다. 향후 연구에서는 몸통 근 육을 포함하여 근활성도를 비교하는 연구가 필요할 것이 라 생각된다.

\section{결론}

본 연구의 목적인 건강한 성인을 대상으로 두 가지 자 세에서 적용한 스쿼트가 하지 근활성도에 미치는 영향을 알아보고 향후 운동 처방의 자료를 제시하고자 하였다. 본 연구에서는 바로 선 자세에서 스쿼트가 무릎 서기 자세에 서 스쿼트보다 넙다리곧은근, 중간볼기근, 넙다리두갈래근 의 근활성도가 증가하는 것으로 나타났으며 큰볼기근의 근
활성도는 감소하는 것으로 나타났다. 따라서 본 연구는 스 쿼트 운동을 통해 특정 근육의 근력 강화를 목표로 할 때 운동 자세의 선택 지표로 활용할 수 있을 것이다. 


\section{이해 충돌}

본 연구의 저자들은 연구, 저작권 및 출판과 관련하여 잠재적인 이해충돌이 없음을 선언합니다.

\section{Acknowledgements}

This study was supported by the Korean Women's Health Physical Therapy Association (2021)

\section{참고문헌}

1. Taichi Kurayama, Yusuke Tadokoro, Shuhei Fujimoto, Zen Komiya, Susumu Yoshida, Sudesna Chakraborty, et al. A comparison of the movement characteristics between the kneeling gait and the normal gait in healthy adults. Gait Posture. 2013;37(3):402-7.

2. Dreeben O. Physical therapy clinical handbook for PTAs. Jones \& Bartlett; 2007.

3. Gillen G. Stroke rehabilitation: a functional-based approach. 3rd ed. Mosbyr; 2010.

4. Umphred D, Carlson C. Neurorehabilitation for the Physical Therapist Assistant. Slack Inc; 2006.

5. Nashner L, McCollum G. The organization of human postural movements: a formal basis and experimental synthesis. Behavioral and Brain Sciences. 1985;8:135-72.

6. Sean Gallagher, Jonisha Pollard, William L Porter. Electromyography of the thigh muscles during lifting tasks in kneeling and squatting postures. Ergonomics. 2011;54(1):91-102.

7. Rinaldo AndréMezzarane, AndréFabio Kohn. Postural control during kneeling. Exp Brain Res. 2008;187(3): 395-405.

8. Vander Linden DW, Wilhelm IJ. Electromyographic and cinematographic analysis of movement from a kneeling to a standing position in healthy 5-to 7-year-old children. Phys Ther. 1991;71(1):3-15.

9. Gallagher S. Trunk extension strength and muscle activity in standing and kneeling postures. Spine. 1997;22(16):1864-72.

10. Harkness EF, Macfarlane GJ, Nahit ES, Silman AJ, McBeth J. Risk factors for newonset low back pain amongst cohorts of newly employed workers. Rheumatology. 2003;42:959-68.
11. Criswell, Cram. Cram's Introduction to Surface Electromyography. 2nd ed. Jones \& Bartlett; 2011

12. Kendall F. Muscle testing and function with posture and pain. 5th ed. Baltimore; 2005.

13. Shabnam Pejhan, Helen C Chong, Liana M Tennant, Stacey M Acker. A comparison of knee joint moments during high flexion squatting and kneeling postures in healthy individuals. Work. 2020;65(1): 79-88. 